\title{
LOS USOS POLÍTICOS DEL CUERPO - LOS DOS CUERPOS DEL REY EN LA FILOSOFÍA POLIITICA DE FRANCIS BACON
}

\author{
Silvia Manzo* \\ silviamanzo@speedy.com.ar
}

RESUMEN Como figure destacada en el complejo escenario político de la transición entre la dinastía Tudor y la dinastía Estuardo de Inglaterra, Francis Bacon (1561-1626) adoptó la teoría de los dos cuerpos del rey en sus textos políticos y jurídicos. Su uso de esta teoría tiene una estrecha conexión con conceptos centrales de su filosofía natural que testimonia la profunda conexión que Bacon encuentra entre la política y la naturaleza. En este trabajo, analizaré su utilización de la teoría medieval de los dos cuerpos del rey y la vinculación que esta tiene con el resto de la filosofía baconiana. Tomaré como eje para el análisis su discurso sobre la naturalización de los escoceses nacidos después de la subida al trono de James I, donde Bacon trata el concepto de los dos cuerpos del rey con más profundidad.

Palabras clave Cuerpo político; Cuerpo natural; Naturalización; Monarquía.

ABSTRACT As a prominent intellectual figure in the complex political arena of England, during the transition from Tudor to Stuart dinasties, Francis Bacon (1561-1626) assumes the medieval King's two bodies theory in his political and juridical writings. His use of this theory is extremely linked to

* Universidad Nacional de La Plata, CONICET, Argentina. Artigo recebido em agosto de 2007 e aprovado em março de 2008. 
central concepts of his natural philosphy, which testifies to the deep connection that Bacon finds between politics and nature. This paper addresses Bacon's use of the King's two bodies theory and its link to the rest of the Baconian philosophy. The focus of this study will be his discourse on the naturalization of Scots born after James I assumption of power, where Bacon deals more deeply with the King's two bodies theory.

Keywords Political body; Natural body; Naturalization; Monarchy.

Hace casi cincuenta años, Ernst Kantorowicz presentaba la teoría de los dos cuerpos del rey, una conceptualización de la soberanía que los intelectuales medievales elaboraron a través de metáforas y máximas originadas en diversos marcos especulativos ligados a la teología. A diferencia del resto de Europa, donde en tiempos modernos la teoría había perdido protagonismo, en Inglaterra fue muy característica de la época isabelina y de los primeros Estuardo. ${ }^{1}$ Esta particularidad se debe a la organización política del reino inglés, en la cual los cuerpos del rey se hacían claramente perceptibles: por un lado el rey, cuerpo natural; por otro lado, el rey en el Parlamento, cuerpo político. ${ }^{2}$

Situado en el complejo escenario político de la transición entre la dinastía Tudor y la dinastía Estuardo, Francis Bacon (1561-1626) adoptó la teoría de los dos cuerpos del rey en sus textos políticos y jurídicos. Su uso de esta teoría tiene una estrecha conexión con conceptos centrales de su filosofía natural que testimonia la profunda conexión que Bacon postula entre la política y la naturaleza. En este trabajo, analizaré su utilización de la teoría medieval de los dos cuerpos del rey y la vinculación que esta tiene con el resto de la filosofía baconiana. Tomaré como eje para el análisis su discurso sobre los post-nati donde el concepto de los dos cuerpos del rey es asumido más expresamente. ${ }^{3}$

2 Kantorowicz 1985, p. 222-223.

3 Las citas de Bacon remiten por un lado a A) Bacon 1859-1864 y B) Bacon 1861-1874. En ambos casos se indica primero el nombre de cada obra particular seguido del número de tomo y del número de página. Todas las traducciones al español son mías. 


\section{El caso de los Post-nati}

Bacon compuso el discurso sobre los post-nati en 1608 a propósito de un pleito muy importante en su época que todavía hoy tiene gran relevancia en la jurisprudencia. ${ }^{4}$ Fue una de las principales controversias surgidas como consecuencia de la unificación de los reinos de Escocia e Inglaterra con motivo de la asunción de James IV de Escocia al trono inglés como James I en 1603. Por entonces, el miedo del Parlamento al absolutismo era creciente; la Casa de los Comunes temía que el rey tratara de concentrar en sí todo el poder. ${ }^{5}$ Por su parte, James deseaba que la unificación no fuera una mera unión de coronas sino también una completa fusión de ambos reinos. Consideraba que tanto ingleses como escoceses eran sus súbditos personales, de modo que no había razón para considerar a los escoceses como extranjeros en Inglaterra. No obstante, la Casa de los Comunes se oponía por razones económicas y políticas. Ante la resistencia parlamentaria, la estrategia de James consistió en evitar que la cuestión de los derechos de los escoceses - de carácter netamente político - recayera en la decisión del Parlamento. Para ello, dispuso de los medios necesarios para que la decisión recayera en la Justicia, presentando una demanda que exigía sentar una doctrina dado que había una laguna jurídica sobre la naturalización. Sin embargo, a pesar de este desplazamiento estratégico hacia los claustros de la Justicia, los argumentos de las distintas facciones parlamentarias fueron tomados en cuenta tanto por los jueces como por los abogados intervinientes.

Así, los abogados de Robert Calvin, un niño escocés nacido en 1606, es decir después de la asunción de James al trono inglés (de ahí la denominación post-natus) presentaron una demanda al King's Bench en reclamo de sus derechos de propiedad sobre unas tierras en Inglaterra, algunas de las cuales le habían sido usurpadas. ${ }^{6}$ Aunque Bacon trató de negarlo, ${ }^{7}$ todo indica que la demanda fue llevada adelante y concertada por la Corona, más allá de que la usurpación realmente se produjo. La primera respuesta de la corte sostenía que dado que Calvin era extranjero, estaba incapacitado para tener dominio absoluto sobre tierras inglesas. Los abogados de Calvin contraargumentaban que el niño era súbdito inglés, en razón de haber nacido después de la asunción de James al Trono de Inglaterra. Ante esta situación el caso fue transferido

4 Sobre las repercusiones del caso vd. Price 1997, p. 1-2.

5 Sobre la cuestión del absolutismo en la Inglaterra del siglo XVII vd. Greenleaf 1964; Daly 1978 y Sommerville 1991.

6 En la reconstrucción del caso Calvin sigo a Coquilette 1992, p. 155-167.

7 Post-nati, A VII, p. 641. 
al tribunal Exchequer (por entonces un tribunal económico) para que fuera analizado por todos los jueces de Inglaterra.

En la discusión que se desarrolló en el tribunal Exchequer se mantuvieron tres posiciones principales. Una posición de máxima a favor de los derechos de los escoceses planteaba que todos ellos, sean post-nati o ante-nati, pasaban a ser ingleses después de la llegada de James I al Trono inglés. La posición opuesta recogía la opinión predominante en la Casa de los Comunes. Sus representantes sostenían que la unificación de tronos en una persona natural individual no era más que una contingencia. Los dos reinos permanecían legal y políticamente separados, sujetos a Parlamentos y a sistemas legales distintos. La única manera de unir los reinos sería a través del consentimiento de los pueblos a través de sus Parlamentos. Finalmente, la posición intermedia sostenía que la naturalización no estaba basada en la lealtad de los súbditos a un sistema particular de leyes, ni en el consentimiento de los súbditos o de sus representantes en el Parlamento, sino "en el vínculo personal de lealtad" que existía entre el súbdito y el monarca. En consecuencia, los ante-nati nunca serían súbditos ingleses, pero los post-nati se convertían en ingleses sin mediación parlamentaria. Esto se debía a que los post-nati habían nacido como súbditos personales de James, como rey de Inglaterra, mientras que los ante-nati lo habían hecho cuando James era solamente rey de Escocia. Francis Bacon fue el portavoz de esta posición.

Bacon estaba muy involucrado en los debates de la unificación tanto en sus aspectos políticos como en los legales. Colaboró con la causa del rey a través de varias intervenciones en el Parlamento y mediante diversos escritos preparatorios para la establecer un único sistema legal. En el caso Calvin en particular intervino como Solicitor-General (subprocurador general de la Corona) cuando la demanda fue llevada al tribunal Exchequer. Organizó su exposición en tres partes, siguiendo el procedimiento que según él es el más adecuado para conducir pleitos: la primera parte consiste en explicar o inducir su posición; la segunda parte, intenta refutar las posibles objeciones a ella; la tercera parte, confirma su posición. ${ }^{8}$

\section{La sumisión natural al rey}

En la primera parte del discurso de Bacon se sintetizan los fundamentos teóricos de su defensa de la naturalización: por un lado, la idea de que la 
sumisión de los súbditos al rey se funda en la ley natural y, por otro lado, la doctrina de los dos cuerpos del rey. La explicación de su tesis se centra en tres temas: el rey, la ley y la naturalización. Desde el comienzo plantea que la monarquía se deriva de ciertos modelos establecidos en la naturaleza e incluso por encima de ella. Uno de ellos es el modelo del padre, quien, por poseer cualidades superiores, gobierna la familia y la servidumbre doméstica ${ }^{9}$ otro modelo de monarquía es el gobierno de Dios sobre la creación, "del cual las monarquías legales son sombras". ${ }^{10}$

Por otra parte, Bacon sostiene que hay cuatro relaciones de sumisión "originales" a la autoridad, es decir, sumisiones que son anteriores a ley civil y establecidas por la ley natural. En ellas se refleja la sumisión "original” del súbdito al monarca, previa a cualquier legislación positiva: 1) la reverencia a la autoridad de los mayores en las sociedades que se rigen por el patriarcado; ${ }^{11}$ 2) la admiración y la gratitud que naturalmente se tiene hacia los hombres de grandes méritos; 3) la veneración que los hombres tienen por quienes han combatido en una guerra para protegerlos; 4) la sumisión de los pueblos a su conquistador, que es una sumisión forzada por el poder que este tiene sobre la vida y la muerte de los conquistados. En tanto naturales, estos tipos de sumisiones deben funcionar como fundamento de la sumisión en el sistema monárquico.

El segundo punto que Bacon desarrolla en la parte de la "explicación o inducción" de su discurso se refiere a la ley. Aquí presenta la doctrina del "doble oficio" de la ley sobre el monarca: por un lado, la ley designa al rey; por otro lado, lo limita en el desarrollo de su poder ordinario. Para ilustrar esta peculiar relación, Bacon retomó imágenes organológicas medievales presentes en la literatura jurídica inglesa. Sin duda, conocía el De Laudibus Legum Angliae de John Fortescue (compuesto en 1470), uno de los tratados jurídicos más importantes de Inglaterra. ${ }^{12}$ Fortescue señala la distinción entre los reinos gobernados "políticamente", esto es, gobernados por el cuerpo político del reino, y aquellos gobernados "monárquicamente", es decir, por el rey solo. Para la constitución de un reino es necesario un rey que gobierne

9 En el modelo patriarcal alude a Aristóteles, Política, III, 14. La traducción latina que cita es muy libre y al parecer pertenece al último párrafo del capítulo 14 (1285b).

10 Post-nati, A VII, p. 644-645. Bacon compara varias veces el gobierno divino con el humano. Cf. por ejemplo en De Augmentis Scientiarum, A I, p. 526-527.

11 La veneración patriarcal está representada en la "fiesta de la familia" narrada en New Atlantis. Cf. Davis 1981, p. 112-113. Cf. Bacon, A Preparation toward the Union of Laws, B VII, p. 737; Gesta Grayorum, A I, p. 340.

12 De Laudibus Legum Angliae fue impreso en 1546. Unos veinte años después, fue traducida al inglés. Coquillette 1992, p. 9. 
todo el cuerpo, pues así como un cuerpo físico necesita de una cabeza, así también el cuerpo místico del reino necesita del rey. ${ }^{13}$ Para Fortescue, la ley es como los nervios en los cuerpos vivos: sostiene el cuerpo místico. Esta analogía ${ }^{14}$ reaparece en la presentación del "doble oficio" de la ley positiva en el discurso de Bacon:

\begin{abstract}
Sin duda la ley es el gran órgano mediante el cual se mueve el poder soberano y puede ciertamente ser comparada con los nervios del cuerpo natural, así como la soberanía puede ser comparada con los espíritus. Ya que si los nervios se encuentran sin espíritus, están muertos y sin movimiento; si los espíritus se mueven a través de nervios débiles, esto produce temblor. De la misma manera, las leyes, sin el poder del rey, están muertas; y el poder del rey, a menos que las leyes sean corroboradas, no se mueve nunca con regularidad, sino que está lleno de tambaleos y trepidaciones. ${ }^{15}$
\end{abstract}

A la metáfora ya conocida de los nervios, Bacon agrega una relevante asimilación del poder real con los espíritus. Esta complejización de la analogía medieval tiene importantes consecuencias en la relación natural entre el rey y el monarca. Para entender mejor los alcances de la analogía conviene dirigir brevemente nuestra atención a la teoría baconiana de los espíritus. Estas entidades ocupan un lugar central en su explicación del funcionamiento de los cuerpos naturales. En la física baconiana los espíritus son sustancias diminutas e imperceptibles constituidas de una materia muy sutil, que se encuentran en todos los cuerpos. Son la causa de su vida y los principales agentes de sus acciones vitales (percepción, alimentación, crecimiento, locomoción, etc.). Hay dos clases de espíritus: los espíritus mortales que luchan por salir del cuerpo y provocan así la muerte; y los espíritus vitales que contribuyen al desarrollo de todas las funciones vitales y luchan contra los mortales. ${ }^{16}$ En los seres vivos ambos espíritus coexisten en constante lucha. La buena salud se alcanza gracias a un equilibrio entre ellos. Cuando el número de espíritus mortales es superior al de los mortales se inicia un proceso que termina en la muerte.

Si aplicamos al extremo la analogía baconiana al contexto político, podríamos establecer una correspondencia entre los dos oficios de la ley positiva y los dos tipos de espíritus. Por un lado, la ley instituye al rey y

13 Kantorowicz 1985, p. 215-216.

14 La analogía parece haber sido común en la época. Por ejemplo, vd. John Hayward A Treatise of Union of the Two Realmes of England and Scotland (London, F.K. for C.B. 1604) citado en Price, n. 222. La referencia a los "nervios" del estado y de la guerra formaban parte del discurso de Lipsius y de Maquiavelo, a los que Bacon hace alusión en otro lugar. Cf. Peltonen 1996, 302-304.

15 Post-nati, A VII, p. 325. Cf. Happy Union, B III, 97.

16 Al plantear esta distinción Bacon se separa de la tradición aristotélico-galénica. Vd. Fattori 1984, p. 292. 
establece las condiciones de la sucesión real (espíritus vitales). Pero, al mismo tiempo, la ley limita los actos del rey, pues éstos se encuentran sujetos a ella para su funcionamiento y su supervivencia (espíritus mortales). La buena salud del reino (de modo similar a la buena salud del cuerpo) consiste en un equilibrio entre la libertad del Parlamento (fuente de la ley positiva, los nervios del cuerpo) y la soberanía del rey (el espíritu que los moviliza). La primera es más pasiva y la segunda más activa. Sin embargo, no se destruyen mutuamente sino que se refuerzan y se mantienen una a la otra. El rey es un dios en la Tierra pero también un dios de tierra: es tan frágil como los otros hombres, puede ser un niño y sufrir enfermedades. Sin la representación de un cuerpo político como el Parlamento, no podría superar estas limitaciones y estaría expuesto a infinitos accidentes. De la misma manera, el Parlamento no es nada sin el rey, no llega por sí mismo a constituirse en el cuerpo político. El Parlamento sin el rey es un "cuerpo opaco". Se convierte en un cuerpo político sólo en tanto recibe y proyecta la luz que proviene del rey. Si se intenta separar al Parlamento (cuerpo político) del rey (cuerpo natural) se extingue la principal "máquina" del Estado. ${ }^{17} \mathrm{El}$ poder del Parlamento no debe excederse porque de lo contrario se acercaría demasiado a la "popularidad."

Ahora bien, la soberanía del rey es anterior a la ley positiva y nace de la lealtad natural que tienen los súbditos hacia él. En rigor, la coexistencia del rey con el Parlamento no hace más que confirmar la ley natural sobre la cual se asienta el consentimiento de sumisión de los súbditos hacia el rey. ${ }^{18}$ Con todo, si bien el poder monárquico es autoritario no llega a ser totalitario:"Si bien el rey en su persona es solutus legibus (libre de las leyes), sin embargo sus actos y derechos están limitados por la ley." 19 Este dualismo refleja la tradición medieval de los dos cuerpos del rey: el rey tiene un poder supremo que le viene de Dios por la ley natural pero a su vez está limitado por la ley común representada en el Parlamento. ${ }^{20}$ De ahí, la ley positiva tiene autoridad por el poder legislador del rey. No hay autoridad en el estado que no provenga de la autoridad del rey y esta proviene inmediatamente de Dios y mediatamente de la ley civil. ${ }^{21}$

17 Bacon, A Speech of General Solicitor..., B IV, p. 178. Bacon usa la expresión "máquina” (engine) en sentido político en varias ocasiones. Por ejemplo en De Augmentis Scientiarum A III, p. 445.

18 Bacon, A Speech of General Solicitor..., B IV, p. 178-180.

19 Post-Nati, A VII, p. 646. Cf. Martin 1992, p. 112-113.

20 Wheeler, 1983.

21 A view of the differences in question betwixt the King's Bench and the Council on the Marches, B III, p. 371373. 
Por lo tanto, el doble oficio de la ley positiva (que instituye al rey) no implica de ningún modo que la lealtad de los súbditos al monarca dependa de una ley positiva. La lealtad al rey depende de una ley natural. No obstante, la ley escrita puede convalidar esa relación. Por eso, dice Bacon, en las antiguas monarquías el rey estaba considerado por encima del legislador. De la misma manera, los hijos no obedecen a sus padres porque lo establece la ley positiva, sino porque se los dicta la razón de acuerdo a una ley natural. Sin embargo, las leyes civiles de las distintas naciones muchas veces confirman esta relación natural de obediencia y respeto de los hijos hacia los padres. Por otro lado, si se quisiera fundar la lealtad en la ley positiva, esta quedaría sujeta a las eventuales variaciones de la ley positiva. En efecto, las leyes positivas de las distintas naciones pueden cambiar, para bien o para mal, debido al paso del tiempo, que es el principal innovador en todas las cosas. La ley positiva puede desviarse de la ley natural. Por eso, los en la cambios legislación deben ser permitidos con gran cautela, pues pueden debilitar "el cuerpo político" y tienen el mismo efecto que los espasmos en el cuerpo natural: el decaimiento y la muerte. ${ }^{22}$ En suma, mediante el uso de la metáfora de los nervios y los espíritus, Bacon relativiza el poder de la ley positiva (nervios), haciéndola depender de la soberanía real natural (espíritus), y enfatiza su idea de que la lealtad al rey proviene de una fuente superior y absoluta, la ley natural. ${ }^{23}$

Como último tramo de la primera parte de su discurso, Bacon se refiere a la tradición legal inglesa sobre la naturalización. Como conclusión sobre este punto establece que tanto por la naturaleza como por la ley positiva la naturalización fue considerada una sujeción personal de los súbditos al rey. Bacon mismo responde a una eventual pregunta sobre la naturalización de los ante-nati: si el rey del cual eran súbditos los escoceses ante-nati ahora ocupa el Trono inglés, ¿no pasan a convertirse ellos mismos en ingleses? Por necesidades claramente políticas, la respuesta de Bacon es negativa. A favor de ella, aduce que la ley natural no se aplica ex post facto, sino sólo simultáneamente, en el momento del nacimiento de cada individuo. De ahí, los ante-nati de Escocia son tan extranjeros con respecto a Inglaterra como lo son los franceses. Aceptar la naturalización de todos los escoceses implicaba

22 Amendments of the Law, B VI, p. 68. La unión de Escocia e Inglaterra fue un cambio excepcional pues no produjo perturbaciones, lo cual es como si ocurriera "fuera del curso ordinario de la naturaleza" vd. Happy Union, B III, p. 91. Una idea similar sobre los peligros del cambio en el cuerpo político se puede encontrar en John Hayward. Cf. Price 1997, n. 214.

23 Price 1997. Bacon no concebía el poder real como absoluto, a pesar de que su defensa de las prerogativas del rey (en polémica con Coke) podría sugerir la contrario. En esta interpretación sigo a Coquillette 1992, p. 286, Wheeler 1990, and Peltonen 1996, p. 284-290; 308. En cambio, Martin 1992, p. 130-131 cree sostiene que en Bacon hay una posición absolutista. 
una serie derechos para estos ciudadanos imposibles de garantizar por parte de la Corona en esa etapa de la unificación. Protegiendo al rey Bacon evitó a toda costa generar más problemas de los que ya de suyo implicaba la naturalización de los post-nati. ${ }^{24}$

\section{Los dos cuerpos del rey}

Bacon sostenía que el rey contaba con dos capacidades: la capacidad política (cuerpo político) y la capacidad natural (cuerpo natural). Su defensa de este principio (compartida con su célebre adversario, Edward Coke) buscaba eliminar por completo una tesis que se había establecido en la Declaración de 1308 según la cual el juramento de lealtad se establece con la Corona más que con la persona del rey. ${ }^{25}$ De ahí, se deducía que cuando las decisiones del rey son nocivas para la Corona se pueden usar medios coercitivos para solucionar sus errores. Esta tesis, que supone una distinción radical entre el rey y la Corona corporativa, cayó rápidamente en desuso en Inglaterra. En oposición a ella, Bacon se remitió a una resolución medieval reportada por Plowden: "en el rey no hay solamente un cuerpo natural, ni solamente un cuerpo político, sino conjuntamente un cuerpo natural y un cuerpo político: corpus corporatum in corpore naturali, et corpus naturale in corpore corporato". ${ }^{26}$ Hay dos cuerpos incorporados en una sola persona real. Con todo, agrega Bacon aludiendo a otro comentario medieval, el hecho de que los dos cuerpos estén unidos no implica que deban ser confundidos, pues es posible distinguir uno de otro. Ciertamente el cuerpo político y el cuerpo natural del rey son distinguibles, pero no son separables, ya que una cosa es la diferencia y otra cosa es la separación. ${ }^{27}$

Entre los juristas ingleses medievales la cuestión de la inseparabilidad del cuerpo natural del rey con respecto a su cuerpo político no siempre fue del todo clara. Una muestra de ello son las indecisiones acerca de la atribución de minoría de edad perpetua a la persona del rey. La tradición del derecho romano establecía que las corporaciones como la república y la Iglesia tenían los mismos derechos que las personas menores. La minoría de edad de las corporaciones tenía importantes consecuencias prácticas: no era afectaba por

24 En otro escrito Bacon explícitamente sostiene que la diferenciación entre ante-nati y post-nati en relación con la naturalización no se funda en la ley sino en la conveniencia política. A Speech used by Sir FB...in the lower house of Parliament. by occasion of a motion concerning the union of laws, B III, p. 339.

25 Kantorowicz 1985, p. 343.

26 Post-nati, A VII, p. 667.

27 Post-nati, A VII, p. 660. 
la prescripción, sus propiedades no podían ser enajenadas ni disminuidas por ninguna persona, el tutor era responsable de la inalienabilidad de su propiedad y recibía una protección especial contra las acciones dolosas o fraudulentas en su contra. Basados en esta tradición, los juristas aplicaron a la Corona la minoría de edad perpetua de las corporaciones mediante la máxima nullum tempus currit contra regem. En la Edad Media la interpretación literal de esta máxima llevó a confusiones, pues llegó a atribuirse la minoría de edad perpetua a la persona del rey, aunque el sentido original era aplicable sólo a la Corona. Más tarde, en plena época Tudor, los juristas afirmaban que el rey en cuanto rey y en cuanto cuerpo político nunca era menor de edad; por la misma razón no sufría de enfermedad, de senilidad ni de muerte. Los corporativistas, por su parte, sostenían que el rey es siempre menor de edad.

Las confusiones son, sin duda, comprensibles porque al parecer se derivan de otros problemas de la política medieval, como por ejemplo la relación entre el cuerpo natural y el cuerpo político. ${ }^{28}$ Para hacer más comprensible ésta relación se introdujo el concepto de Dignidad que se refería principalmente a la singularidad del cargo real, a la soberanía investida en el rey por el pueblo, la cual recaía individualmente sólo en el rey. La Dignidad no sólo concernía a la persona privada del rey sino también a la persona pública de todo el reino. Para llegar a definirla con claridad era necesario distinguirla de la persona natural del rey, lo cual requirió de arduas reflexiones durante siglos. Precisamente por ello, de algún modo la Dignidad se confrontaba con la doctrina de los cuerpos del rey, pues ésta última asume que la persona ficta (cuerpo político) ocupa el mismo lugar que la persona real (cuerpo natural) suponiendo así una suerte de unión hipostática secularizada. De esta manera unificaba físicamente cosas que estaban separadas conceptualmente a través del concepto de Dignidad. ${ }^{29}$

Un lejano eco de estas dificultades puede advertirse en los escritos de Bacon. A pesar de su propia prescripción de evitar la confusión entre el cuerpo natural y el cuerpo político del rey, él mismo tiende a fusionar al rey, cuerpo natural, con el cuerpo político. La terminología que utiliza, especialmente cuando explica el tipo de relación recíproca que tiene lugar entre ambos cuerpos, da cuenta de sus difusos conceptos de la persona natural del rey y del cuerpo político. Bacon habla literalmente de una relación de "influencia o comunicación de cualidades", concepto que forma parte de la teoría medieval. ${ }^{30}$

28 Estas confusiones son ciertamente consecuencia de la utilización de la metáfora corporal que, al basarse en "argumentos por correspondencia", generaba múltiples y hasta opuestas interpretaciones. Cf. Greenleaf 1964, p. 757-758.

29 Kantorowicz 1985, p. 359-382.

30 Post-nati, A VII, p. 668-669. 
Por un lado, enumera la serie de "perfecciones" que "el cuerpo político de la Corona introduce en la persona natural del rey". Cuando Bacon presenta las perfecciones deja de hablar de "la persona natural" para decir "the king in law" y confunde de esta manera el cuerpo natural con el cuerpo político. ${ }^{31}$

Las perfecciones recibidas modifican el carácter natural del rey en lo siguiente: el rey ante la ley no está sujeto a los cambios de edad, ni a la corrupción natural, ${ }^{32}$ y si antes de acceder al Trono estuviera condenado, la condena queda anulada en el momento mismo de la accesión. Los bienes son recibidos por el rey de hecho, a manera de don en vínculo con su calidad de rey. El cuerpo del rey ante la ley se convierte en inmortal; en él no se da la muerte sino una demise, ${ }^{33}$ de manera que sigue vivo mediante un peculiar traspaso de poder. ${ }^{34}$ Esta idea de demise, que Bacon toma de la tradición medieval inglesa, tiene un significado muy específico en su aplicación a la persona del rey ante la ley. En los reportes de Plowden encontramos una definición muy clara de éste concepto: "Demise es una palabra que significa que hay Separación entre los dos cuerpos; y que el Cuerpo político se traslada de un Cuerpo natural, ahora muerto o desprovisto de la Dignidad real, a otro Cuerpo natural." 35

En cuanto a la comunicación de cualidades en sentido opuesto (es decir, del cuerpo natural al cuerpo político), hay una que Bacon destaca como la más importante: la continuidad dinástica por herencia. Este rasgo convierte al cuerpo político del rey en una corporación distinta de las restantes corporaciones del reino, sean éstas temporales o eclesiásticas, unipersonales o colectivas. En efecto, la continuidad dinástica se establece por herencia, no por sucesión como sucede en la Iglesia y en otras corporaciones. Por lo tanto, no cabe transpolar la situación jurídica de los obispos y los párrocos a la Corona. Dado que el cuerpo natural del rey tiene descendientes, la Corona tiene su continuidad de la misma manera que los cuerpos naturales, a través de herederos - no a través de sucesores. ${ }^{36}$

A diferencia de las otras corporaciones, donde la persona natural no es más que un instrumento para mantener y sostener el cuerpo corporativo, en la corporación de la Corona el cuerpo natural del rey tiene peso e influencias

31 A lo largo del discurso Post-nati Bacon utiliza varias denominaciones cuando se refiere al sujeto que recibe las perfecciones del cuerpo político de la Corona: "the king in law"; "the king "; "his body in law"; "king's natural person".

32 En consonancia con la tradición absolutista que realza el carácter excepcional de la sangre real, Bacon sostiene que la sangre del rey nunca se corrompe, Post-Nati, A VII, p. 667. Cf. Kantorowicz 1985, p. 314, n. 64.

33 En la actualidad en el vocabulario jurídico inglés demise significa transmisión de la Corona por sucesión.

34 Post-nati, A VII, p. 668.

35 Plowden Reports, p. 233a citado en Kantorowicz 1985, p. 51; cf. ib., p. 24-25.

36 Post-nati, A VII, p. 668. 
propias. ${ }^{37}$ Bacon se detiene a exponer ciertos casos en los que la Corona como corporación está implicada en ciertas relaciones que, en rigor, le competen a una persona natural. Por ejemplo, los hijos y esposos del monarca tienen parentesco con el cuerpo natural del rey. Sin embargo, ellos también son personas públicas ya que se considera traición atentar contra su vida, como si fueran parte del cuerpo político. Por el contrario, la familia de un obispo, por ejemplo, no es afectada en sentido alguno ante la ley en razón de la corporación formada por el obispo, ya que una corporación, en sentido estricto, no tiene esposos ni hijos. Otra influencia del cuerpo natural del rey sobre el cuerpo político señalada por Bacon tiene que ver precisamente con la cuestión de la naturalización, aplicable al caso concreto de James I y sus súbditos. La lealtad de los súbditos escoceses hacia la persona natural de James hace que éstos queden ligados con sus súbditos ingleses, estableciéndose entre ingleses y escoceses una relación más íntima que la anterior. En consecuencia, los ingleses y los escoceses unidos a través de su lealtad a un mismo rey nunca se verán como enemigos entre sí: "la persona natural del rey tiene tal comunicación de cualidades con su cuerpo político que hace que los súbditos de cada reino mantengan un grado de relación unos con otros distinto del que tenían antes". 38

\section{Los argumentos en el debate judicial}

Terminada la exposición de argumentos positivos, Bacon se dedicó a la parte negativa de su discurso: la consideración de las objeciones contra la naturalización y la refutación de las mismas. Reduce las objeciones a cuatro. La primera sostiene que en verdad la lealtad de los súbditos no se establece con el cuerpo natural del rey, sino con su cuerpo político. Por lo tanto, si la lealtad se establece con la ley de Inglaterra, entonces los que nacen fuera del reino de Inglaterra no pueden ser súbditos de su ley. ${ }^{39}$ En contra de este argumento positivista, ${ }^{40}$ basándose en la tradición legal Bacon afirma que la ley de Inglaterra tiene imperio en todo el mundo. La aplicación extraterritorial de la ley nacional, era necesaria en casos como la naturalización, pues de lo contrario, se caería en el absurdo de que los hijos de ingleses nacidos en el extranjero no podrían ser ingleses.

40 Positivista en germen, ya que supone que una ley impera sólo allí donde puede ser reforzada por sanciones. Cf. Coquillette 1992, p. 161. 
La segunda objeción a la naturalización que Bacon refuta retoma un argumento muy discutido propuesto por John Bennet, un jurista formado en el derecho romano que había sido consultado por el Parlamento a propósito del caso Calvin. ${ }^{41}$ Bennet sostenía que la ley civil no tenía elementos para resolver el problema de la naturalización de los post-nati. Sin embargo, creía que podía aplicarse una máxima del derecho romano destinada a uniones de menor envergadura que la unión de dos reinos y sistemas legales en una sola persona natural. La máxima dice: "cuando dos derechos concurren en la misma persona es lo mismo que si estuvieran en personas distintas". ${ }^{42} \mathrm{En}$ la interpretación de Bennet esta máxima se podría aplicar, por ejemplo, a un párroco que dirige dos parroquias distintas. Ya que la máxima establece que es como si tales funciones recayeran en personas distintas y no en el mismo párroco, entonces los fieles de una parroquia no están vinculados con los fieles de la otra como si pertenecieran a una misma comunidad comandada por la misma persona. Aplicado este ejemplo a los post-nati, ya que los derechos y costumbres de cada país siguen separados después de la unión de coronas en el mismo cuerpo natural, los post-nati no tienen más derecho a reclamar la naturalización que los ante-nati..$^{43}$ Así, basados en la máxima Cum duo jura... los opositores a la naturalización aducían que, dado que la lealtad se establece con el cuerpo político del rey y dado que los cuerpos políticos de Escocia e Inglaterra permanecían separados después de la unión de las coronas, los súbditos nacidos en Escocia tanto antes como después de 1603 eran indefectiblemente escoceses.

La argumentación de Bacon para refutar estos razonamientos es poco clara. Bacon sostiene que esta máxima no se puede aplicar en los casos de la ley común en los que está implicada una persona natural. Para ello hace una comparación entre la relación del vasallo con el señor feudal, y la relación del súbdito con el rey porque las considera de una "naturaleza similar". Señala que en caso de que un vasallo reciba dos tierras distintas del mismo señor, no debe reverenciar dos veces al mismo señor. Esto es así porque el hombre tiene una sola conciencia y no tiene sentido jurar lealtad dos veces a la misma persona. La lealtad se establece entre la persona natural del vasallo y la persona natural del señor. De la misma manera, la lealtad de un súbdito se establece con el cuerpo natural del rey, que es inescindible del cuerpo político. Por lo tanto, cuando esa misma persona natural reúne en sí distintos sistemas legales

41 Price 1997, p. 24

42 Post-nati, A VII, p. 657: Cum duo jura concurrunt in una persona aequum est ac si essent in diversis.

43 Price 1997, analiza con detalle la discusión en torno a esta máxima. 
representados en dos cuerpos políticos distintos, el súbdito tiene lealtad con ellas también por el hecho de haber jurado lealtad a la persona natural.

La tercera objeción refutada por Bacon se dirige a los supuestos inconvenientes económicos y sociales que acarrearía la naturalización de los post-nati, que resumen gran parte de los motivos que ocasionaron la resistencia de la Casa de los Comunes. Por un lado, Bacon desmiente que las arcas del fisco fueran a perder beneficios significativos y que haya de ocurrir una migración masiva de escoceses a Inglaterra, aludiendo al hecho de que, desde la unificación, muy pocas familias escocesas se afincaron en ciudades inglesas. ${ }^{44}$ Por otro lado, si eventualmente ocurriera que el monarca tuviera súbditos personales de otras lenguas y culturas (como de hecho podía ser el caso de los habitantes de las colonias de Norteamérica), determinar si también ellos deben ser naturalizados será una decisión de carácter político y no legal. ${ }^{45}$

La última refutación que Bacon emprende niega que la naturalización sea distinta cuando se trata de habitantes de un reino que ha sido anexado por la herencia monárquica (caso de Escocia, que fue anexada porque la sucesión le correspondía a James IV dada que Elizabeth I no tenía descendencia) que cuando se trata de un reino anexado por conquista (caso de Irlanda). Su exposición analiza con mucho detalle las condiciones legales de cada situación y concluye que la conquista no debe implicar la naturalización automática y que, por otro lado, no hay razón para negar sistemáticamente la naturalización para los territorios que se anexan por la línea de descendencia. Hay sola una misma razón que justifica ambas naturalizaciones: la unión en la persona natural del rey. ${ }^{46}$

Refutadas las objeciones, en la última parte de su discurso, Bacon se dedica a presentar tres "pruebas" que muestran que los post-nati son ciudadanos ingleses de acuerdo con la ley de Inglaterra. La primera prueba se basa en la ley natural y sostiene que la ley es ecuánime y no favorece a unos hombres más que a otros. En verdad, la ley no protege a las personas sino sólo a los bienes de que son pasibles. Hay tres bienes supremos que la ley civil contempla basándose en la ley natural: la vida - ya que existe un instinto universal de preservación de la vida -; la libertad -que todo animal busca y valora-; y la dote - es decir la sociedad del hombre con la mujer, de

44 En A Speech used by Sir Francis Bacon in the Lower House of Parliament concerning the article of naturalization, B III, p. 309-313, Bacon contesta con más detalle estas objeciones.

45 Post-nati, A VII, p. 658-663.

46 Post-nati, A VII, p. 659-663. 
la cual la surge la dote como recompensa. Bacon alude aquí a la revelación de las Escrituras para apoyar su interpretación de la ley natural. Todos los hombres fueron hechos con la misma materia y por el mismo soplo de Dios, tuvieron padres comunes y fueron naturalizados por ley natural unos con respecto a otros. En un principio todos compartían la misma lengua, hasta que como consecuencia del primer pecado, se perdió la comunidad lingüística y comenzaron a distinguirse las naciones. Con la disolución de la lengua común y la formación de las naciones, se instituyó la ley civil de cada nación, que se deduce de la ley natural, razón por la cual ninguna nación debe ser favorecida por sobre otra. Fue la ley civil la que instauró las palabras civis y exterus, nativo y extranjero, reduciendo los principios de la ley natural. Así, Bacon insiste en que la legislación civil inglesa debe favorecer la naturalización ya que esta se deriva de la ley natural según la cual en los primeros tiempos de la humanidad todos los hombres estaban "naturalizados" entre sí y no había todavía distinción entre naciones. Obviamente, Bacon tenía en cuenta las consecuencias políticas de una legislación proclive a la naturalización. Los hechos muestran, según él, que las naciones más abiertas y generosas para la naturalización son las más magnánimas y guerreras, las más adecuadas para la formación de un imperio (con el cual Bacon soñaba). En cambio, las naciones mercantiles cerradas han corrido peor suerte.

La segunda prueba que ofrece Bacon, en primer lugar, indica que según la ley inglesa las condiciones para ser natural inglés son que haya un rey y que el individuo sea natus ad fidem regis (nacido con lealtad al rey). A esta base de la ley positiva, en segundo lugar, Bacon agega tres pruebas fundamentales que implican la naturalización de los post-nati: 1) La lealtad se establece entre los súbditos y la persona natural del rey, no con el reino ni con la ley positiva. Por lo tanto, no puede depender de aquello sin lo cual puede existir por sí misma. Es decir, no puede depender de la ley civil. ${ }^{47} 2$ ) Existe una influencia bidireccional entre los dos cuerpos del rey. El cuerpo natural del rey tiene influencia y capacidad de operar sobre su cuerpo político, de la misma manera que su cuerpo político modifica al cuerpo natural. De ahí, si bien el cuerpo político del rey de Inglaterra y el cuerpo político del rey de Escocia son dos y distintos, su cuerpo natural es único, de modo que influye y crea una comunicación entre ambos. La naturalización es una relación entre los súbditos y el cuerpo natural. 3) Hay textos de cinco estatutos ingleses que confirman la naturalización interpretada en este sentido. 
En la justificación de la segunda prueba Bacon enfatiza que la lealtad tiene su último sustento en la ley natural. Afirma que la lealtad "comenzó antes de la leyes, continúa después de las leyes y está en vigencia donde las leyes están suspendidas y no tienen fuerza". ${ }^{48}$ Que la lealtad existe antes de la ley civil se confirma entre otras cosas por el hecho de que los súbditos veneran a sus monarcas sin que haya una legislación que lo prescriba, así como los hijos obedecen a sus padres sin necesidad de que los obligue la ley escrita. Que la lealtad existe después de la ley se confirma por el hecho de que (como fue establecido por los jueces de Inglaterra) si el rey fuera expulsado de su reino y algún súbdito conspirara contra su vida durante su exilio, una vez recuperado el reino, el monarca tiene derecho a procesar al súbdito por traición según la ley de Inglaterra.

Finalmente, que la lealtad al rey continúa cuando la ley positiva no está en vigencia se muestra en las guerras. En este punto, Bacon se alude a la distinción de origen medieval entre poder absoluto y poder ordinario del rey, inspirada en la distinción teológica de poder absoluto y poder ordinario de Dios. ${ }^{49}$ En la guerra la soberanía del rey, lejos de ser anulada o reducida, alcanza su plenitud y puede desplegar sus poderes extraordinarios sin el control de la ley civil, ya que Silent leges inter arma (entre las armas las leyes hacen silencio). ${ }^{50} \mathrm{El}$ rey puede proceder por ley marcial con autoridad suprema, sin tener que atender a las formalidades de las leyes de su reino.

Por lo tanto, continúa Bacon, quien habla de las leyes, del poder del rey a través de ellas, y de la obediencia de los súbditos o sumisión a las leyes, sólo se refiere a una mitad de la Corona. Es en este sentido que Bacon cree que han de interpretarse las doctrinas de Bracton y de Justiniano, quienes sostienen que la Corona está compuesta por las leyes y por las armas, es decir por el poder civil y por el poder marcial. Con el poder de las armas la ley no se inmiscuye. En la guerra los súbditos no se rigen por la ley civil sino por la ley marcial, establecida por la exclusiva prerrogativa del rey. De otra manera, se daría el caso de que ciudadanos ingleses y escoceses, cuyas leyes civiles son distintas pues responden a distintos cuerpos políticos del rey, cuando están enfrentando a un enemigo común en la guerra no tendrían ley (civil) común

48 Post-nati, A VII, p. 665

49 Sobre el sentido y el origen teológico de estas categorías vd. Oakley, 1968 y 1984.

50 Post-nati, A VII, p. 666. Para Bacon las guerras justas son necesarias para la buena salud del cuerpo político, así como el ejercicio es necesario para el cuerpo natural. Cf. De Augmentis Scientiarum, A I, p. 800-801. 
a la cual respetar. ${ }^{51}$ De modo que, en caso de guerra, tanto los ingleses como los escoceses están sometidos a una única ley, la ley natural que los une con su monarca.

Bacon cierra su discurso repitiendo las palabras que según él "un buen padre" dijo acerca las Iglesias de Cristo: si son inseparables son insuperables. ${ }^{52}$ Si los dos reinos de Escocia y de Inglaterra permanecen inseparablemente unidos en la cabeza de su rey y si los que nacen durante esa unión son naturalizados y vinculados estrechamente entre sí, en tanto súbditos leales a un mismo cuerpo natural, entonces esos reinos jamás serán conquistados por ninguna fuerza extranjera.

Terminado el debate, los argumentos de Bacon se coronaron con el éxito. Hubo sólo dos votos en contra de la naturalización. En consecuencia, el tribunal convalidó la teoría medieval de la lealtad personal al cuerpo natural del rey y los post-nati fueron naturalizados como ingleses.

\section{Los paralelos entre la política y la naturaleza}

La tradición medieval de los dos cuerpos del rey se integra perfectamente en la filosofía baconiana. Bacon supone que existe una analogía o consenso universal entre todos los compartimentos de la realidad. Por eso sostiene que entre las distintas esferas del saber se da una "continuidad". Las ciencias particulares están comunicadas a través de una serie de leyes generalísimas (axiomas) compartidas por todas ellas. La filosofía primera es la ciencia que está en la base de todas las ciencias particulares y que recoge el conjunto de esos axiomas. Tiene la misión de proveer la información que conecta las ciencias entre sí, ayudando a su buen crecimiento y a su mutua rectificación. De la misma manera que las partes y los miembros de una ciencia dependen de las máximas de la misma, así también, las diversas ciencias, para ser aumentadas y perfeccionadas, dependen de un conocimiento universal que las abarca a todas..$^{53}$

51 Sobre las prerrogativas del rey y su relación con las ideas imperialistas de Bacon vd. Martín 1992, p. 129134.

52 Bacon no aclara quién es el autor de la frase. Post-nati, A VII, p. 679.

53 Este idea de la continuidad de las ciencias está presente en uno de los primeros escritos de Bacon sobre filosofía natural, el Valerius Terminus A III, p. 229, escrito en la misma época que los textos sobre la unificación, y persiste en el resto de su obra. Cf. Bacon, De Augmentis Scientiarum, A I, p. 540-543, 580; The Advancement of Learning , A III, p. 367. Sobre este tema vd. Jardine 1974, p. 96-103; Whitney 1986, p. 62-67; Kusukawa 1996, p. 54-56. En Manzo 2002, analizo algunas de las dificultades que encuentro en el planteo de Bacon sobre la continuidad de las ciencias. 
Dado este principio ontológico y su correlato epistemológico, es muy habitual que Bacon extrapole teorías y ejemplos de la naturaleza a la sociedad humana a la vez que vincula la filosofía natural con la filosofía política. En un discurso escrito a propósito de la unificación de Escocia e Inglaterra, A briefe discourse touching the happy union of kingdoms of England and Scotland (1603) hace explícita esa vinculación. Allí, Bacon señala que la unión de Escocia e Inglaterra afecta tanto los cuerpos políticos como los cuerpos naturales de ambos reinos y agrega que existe una afinidad y un consenso entre las verdaderas reglas de la naturaleza y las verdaderas reglas de la política. La naturaleza debe, entonces, ser bien conocida por la ciencia para que pueda funcionar como un modelo que debe ser imitado por la política. ${ }^{54}$

En el consenso que enlaza la naturaleza con la política Bacon destaca una ley fundamental compartida por ambas: el predominio del bien común sobre el bien individual. Según ésta ley el bien común impera sobre los apetitos privados y los subordina, porque tiene como fin que la totalidad del universo (natural o político) subsista. ${ }^{55}$

Con respecto a la unión de Escocia e Inlgaterra, Bacon sostiene que hay que contemplar en la naturaleza cómo son las uniones entre las sustancias y sacar de ahí conclusiones aplicables a la política. Las uniones tanto entre cuerpos políticos como entre cuerpos naturales pueden obtenerse por medios violentos o por medios naturales. La unión política violenta -es decir, la unión por conquista - ocurre cuando un reino somete a otro y lo modifica haciéndolo semejante a sí mismo, extinguiendo y expulsando todo lo que no se adapte a él. En la naturaleza, una acción violenta semejante es la que ejerce el fuego cuando quema la madera, pues convierte la madera en fuego, y expulsa el humo y la ceniza porque no son inflamables. A partir de esta conceptualización, Bacon concluye que la unión de Inglaterra y Escocia no fue violenta sino natural.

Además, agrega que las uniones naturales adquieren distintos grados de perfección. Para hacer una tipología de uniones por medios naturales, Bacon adopta las clasificaciones aristotélicas de las uniones entre los cuerpos físicos y las compara con las uniones políticas. En la naturaleza se distingue la composición (compositio o corpus imperfecte mixtum) de la mezcla (mixtio). En la primera, dos cuerpos se combinan formando un cuerpo heterogéneo, de manera que sus corpúsculos nunca se funden unos con otros, sino que simplemente se distribuyen ubicándose uno al lado del otro (se con-ponen).

54 Bacon, A briefe discourse touching the happy union of kingdoms of England and Scotland (en adelante, Happy Union) B III, p. 90.

55 Happy Union, B III, p. 91. Cf. Bacon, De Augmentis Scientiarum A I, p. 717, 541-542. 
En la mezcla, las partículas se combinan de tal manera que forman un nuevo cuerpo homogéneo, en el cual no se puede distinguir las partes puras de los originales. Para analizar fenómenos dentro de esta tipología Bacon adhiere expresamente a la tradición alquímica, según la cual las sustancias naturales se agrupan en tres grandes familias: sal, sulfuro y mercurio. ${ }^{56}$ Cuando sustancias de distintas familias están imperfectamente unidas en un compuesto, se separan con facilidad. Cuando, por el contrario, están homogéneamente mezcladas en un mineral o un vegetal se necesita gran fuerza y sutilidad para separarlos "ya que la nueva forma es un vínculo común". ${ }^{57}$ Las partes de un compuesto pueden ser fácilmente separadas y así recuperar los cuerpos que la integran en su estado original. La mezcla, en cambio, es más permanente.

La verdadera unión política, como la que James I alcanzó, es semejante a la mezcla, madre de la paz y de la continuidad. En ella, se engendra un nuevo reino pues "introduce una nueva forma, agradable y conveniente para todo el Estado". Por el contrario, la composición en sentido político es sólo una conjunción de soberanías que no llega a alcanzar una fusión estable para conformar un solo cuerpo político; esta unión imperfecta es una confusión de dos reinos que tarde o temprano conduce a la sedición. ${ }^{58}$ Pero, ya que esta mera conjunción de soberanías es más fácil de alcanzar que una verdadera unión, lo más habitual a lo largo de la historia han sido las uniones imperfectas. Hay, en cambio, pocos ejemplos de verdaderas uniones: estas son sin duda más difíciles de lograr pero más felices. ${ }^{59}$

Finalmente, Bacon señala dos requisitos necesarios para la obtención de una perfecta mezcla tanto en la política como en la naturaleza: 1) El transcurso del tiempo, pues -como dicen los filósofos naturales - "la composición es obra del hombre y la mezcla es obra de la naturaleza". La tarea del hombre es hacer una adecuada conjunción de los cuerpos entre sí, pero su "fermentación e incorporación" deben ser dejadas a la naturaleza y al tiempo, que convierten en continuum lo que al principio era sólo contiguum. 2) "El más grande debe arrastrar al más pequeño"; como un río pequeño que, cuando confluye en otro más grande, pierde su nombre y su cauce para adaptarse a los del mayor. ${ }^{60}$ Bacon confiaba en que la unión entre las leyes de Escocia e Inglaterra podía ser perfecta dado que los elementos de sus sistemas legales podía alcanzar

56 En otros textos Bacon excluye la sal. Cf. Historia Sulphuris, Mercurii et Salis, A II, p. 82.

57 Happy Union, B III, p. 93-94.

58 Esta metáfora de la unión corporal aplicada a la política aparece también en la defensa que Bacon hace de las prerrogativas del rey. Cf. A Speech of the King's Solicitor..., B IV, p. 177.

59 Happy Union, B III, p. 95-96.

60 Happy Union, B III, p. 98. 
"un temperamento excelente en su composición". ${ }^{61}$ Dado el transfondo del caso Calvin, Bacon creía en su fuero íntimo que el proceso de unificación de Escocia e Inglaterra había alcanzado tan sólo una composición imperfecta. Ni siquiera se habían unificado los sistemas legales ni el Parlamento y faltaba mucho tiempo para que el "más grande" (Inglaterra) pudiera arrastrar en su cauce al "más pequeño" (Escocia). De hecho, tenía la impresión de que el rey estaba precipitando una "mezcla" de los reinos con mayor celeridad que la conveniente. ${ }^{62}$ Antes de que el tiempo y la naturaleza hicieran su trabajo para lograr la mezcla, era necesario que la tarea de composición previa se terminara de completar mediante la intervención del hombre a través de las instituciones políticas y del rey. Con su intervención en el caso Calvin Bacon intentó contribuir con esta tarea.

\section{Conclusión}

Bacon pensaba que la realidad se estructuraba a partir de un consenso general en el que las mismas leyes generalisimas comunicaban todos los ámbitos del ser. En este entramado, la buena política necesariamente debe tomar como modelo la naturaleza. Es por ello que una teoría como la de los dos cuerpos del rey encuentra tan buena cabida en el pensamiento jurídico y político de Bacon. No se trata solamente de que Bacon se apropió de esta construcción teórica medieval porque servía a los intereses políticos que quería defender. Se trata, además, de la utilización de la ficción medieval dentro de una concepción filosófica general sobre la realidad que es perfectamente compatible con ella.

No obstante, la concepción de los dos cuerpos del rey no se inspira en la misma fuente que la filosofía política baconiana. En Bacon la regla que dirige el diseño de la filosofía política es la filosofía natural. En cambio, es la teología la fuente que predomina en la construcción de la teoría de los dos cuerpos del rey. Amos Funkenstein ha señalado que las metáforas organolépticas y corporativas que fueron características de la tradición política medieval fueron reemplazadas en la Modernidad por metáforas predominantemente mecanicistas. ${ }^{63}$ Retomando esta perspectiva, podríamos sostener que el

61 A Speech used by Sir FB...in the lower house of Parliament by occasion of a motion concerning the union of laws, B III, 335.

62 Introducción de Spedding a Happy Union, B III, 89.

63 Funkenstein 1986, p. 271. 
universo de Bacon es "protomecanicista" y que así también parecen serlo sus metáforas políticas.

El pensamiento político de Bacon está indisolublemente ligado a su preocupación central por la ciencia natural. Se sitúa en una era donde la mirada del hombre deja de tener como centro el problema de Dios, aunque ésta nueva perspectiva no llegó a desligarse completamente de él. Es por ello que el marco de referencia fundamental de la reflexión política baconiana no puede ser ya la teología, más allá de que ella está en el margen de su especulación. Los escritos baconianos consideran que la filosofía natural es la rama principal del saber, en el que se funda todo conocimiento y toda acción. Por ello, la política no puede más que mirar la naturaleza e imitarla. Acaso hay en ello un lejano eco de la concepción griega del arte como imitación de la naturaleza. En el caso de los dos cuerpos del rey Bacon incopora, como tantas otras veces, una teoría ajena a las raíces intelectuales de sus propias ideas. Lo hace porque la considera una pieza que se ajusta sin dificultad al edificio de su vasta filosofía. El resultado es, sin duda, una complicada construcción ecléctica animada por una clara intencionalidad política. Precisamente en ello reside uno de los mayores atractivos de la filosofía baconiana. Ella constituye un claro exponente tanto de la compleja red teórica como de la interacción que ésta tuvo con los hechos e intereses políticos y sociales que operaron en la base de la filosofía de Occidente en su transcurso del Medioevo a la Modernidad.

\section{Bibliografía}

Bacon, Francis, 1859-1864, The Works of Francis Bacon, collected and edited by James Spedding, Robert Leslie Ellis and Douglas Denon Heath, 7 vols., Longman and Co, Londres.

Bacon, Francis, 1861-1874, The Letters and Life of Francis Bacon edited by James Spedding, 7 vols., Longman and Co., Londres.

Coquilette, Daniel R., 1992, Francis Bacon, U.P. Melksham, Edimburgo.

Daly, James, 1978, "The Idea of Absolute Monarchy in Seventeenth-Century England", The Historical Journal, vol. 21, n. 2, p. 227-250.

Davis, J. C., 1981, Utopia and the Ideal Society. A Study of English Utopian Writing 1516-1700, Cambridge University Press, Cambridge.

Fattori, Marta, 1984, "Spiritus dans 1" Historia Vitae et Morti de F. Bacon" en id. Spiritus, Edizioni dell' Atteneo, Roma, Lessico Intelletuale Europeo, p. 283-323. Funkenstein, Amos,1986, Theology and the Scientific Imagination from the Middle Ages to the Seventeenth Century, Princeton University Press, Princeton, Nueva Jersey. 
Greenleaf, Richard, 1964, "The Thomasian Tradition and the Theory of Absolute Monarchy", The English Historical Review, vol. 79, n. 313, p. 747-760.

Hobbes, Thomas, 1992, Leviatán o la materia, forma y poder de una república eclesiástica y civil, trad. y prefacio Manuel Sanchez Sarto, FCE, México.

Kantorowicz, Ernst, 1985, Los dos cuerpos del rey. Un estudio de teología política medieval, Alianza, Madrid. Primera edición Princeton University Press, 1957.

Jardine, Lisa, 1974, Francis Bacon. Discovery and the Art of Discourse. Cambridge University Press, Cambridge.

Kusukawa, Sachiko, 1996, "Bacon's Classification of Knowledge" en M. Peltonen, The Cambridge Companion to Bacon, Cambridge University Press, Cambridge, p. 47-74.

Manzo, Silvia, 2002, "Una elección de teorías en el siglo XVII: Francis Bacon y los sistemas astronómicos", en P. Lorenzano y F. Tula Molina, Filosofía e Historia de la Ciencia en el Cono Sur, Universidad Nacional de Quilmes, Bernal, p. 287-295.

Martin, Julian, 1992, Francis Bacon, The State and the Reform of Natural Philosophy, Cambridge University Press, Cambridge.

Oakley, Francis, 1968, "Jacobean Political Theology: The Absolute and Ordinary Powers of the King", Journal of the History of Ideas, vol. 29, n. 3, p. 323-346.

Oakley, Francis, 1984, Omnipotence, Covenant, and Order. An Excursion in the History of Ideas from Abelard to Leibniz, Cornell University Press, Ithaca y Londres. Oxford Dictionary of Law, 1997, ed. by Elizabeth A. Martin, Oxford University Press, Oxford-Nueva York.

Peltonen, Markku, 1996, "Bacon's political philosophy" en id., The Cambridge Companion to Bacon, Cambridge University Press, Cambridge, p. 283-310.

Price, Polly J., 1997, "Calvin's Case”, Yale Journal of Law \& the Humanities, Winter 1997, 9 Yale J.L. \& Human. 73. Citado de version electrónica: <http://www.geocities. com/b_rookard/calvins_case.html>.

Sommerville, J. P., 1991, “Absolutism and Royalism”, en J. H. Burns editor with the assistance of Mark Goldie, The Cambridge History of Political Thought, 1450-1700, Cambridge Unviersity Press, Cambridge, p. 347-374.

Yates, Frances, 1985, El Iluminismo Rosacruz, traducción Roberto Gómez Ciriza, Fondo de Cultura Económica, México. Primera edición Routledge and Kegan Paul Ltd., Londres, 1972.

Weston, Corine, 1991, "England. Ancient Constitution and Common Law" en J. H. Burns editor with the assistance of Mark Goldie, The Cambridge History of Political Thought, 1450-1700, Cambridge Unviersity Press, Cambridge, p. 375-411.

Wheeler, Harvey, 1983, "The Invention of Modern Empiricism: Juridical Foundations of Francis Bacon's Philosophy of Science”, Law Library Journal, vol. 76, p. 78-122. Wheeler, Harvey, "Francis Bacon's Case of the Post-Nati ,1608); Foundations of Anglo-American Constitutionalism; An Application of Critical Constitutional Theory", edición electrónica. 
Wheeler, Harvey, 1990, "Francis Bacon's New Atlantis: The 'Mould' of a Lawfinding Commonwealth", en W. Sessions, Francis Bacon's Legacy of Texts, AMS Press, Nueva York, p. 291-310

Whitney, Charles, 1986, Francis Bacon and Modernity, Yale University Press, New Haven-Londres.

Wootton, David, 1991, "Leveller Democracy and the Puritan Revolution" en J. H. Burns editor with the assistance of Mark Goldie, The Cambridge History of Political Thought, 1450-1700, Cambridge University Press, Cambridge, p. 412-442. 